\title{
In-Line Incomplete Solid-Liquid Extraction for Spectrophotometric Determination of Soluble Inorganic Phosphorus in Plants and Foods
}

\author{
Caio C. V. Macedo, ${ }^{a}$ Rodrigo S. N. Mancini, ${ }^{a}$ Carolina Y. Arakaki ${ }^{a}$ and Diogo L. Rocha*,a \\ ${ }^{a}$ Centro de Ciências Naturais e Humanas, Universidade Federal do ABC, \\ 09210-580 Santo André-SP, Brazil
}

\begin{abstract}
Phosphorus determination in plant materials and foods is important. For accessible inorganic $\mathrm{P}$ assessment, solid-liquid extraction (SLE) is required. In this work, a flow-based analytical procedure employing zones penetration approach was developed aiming at the soluble inorganic phosphorus $\left(\mathrm{P}_{\mathrm{I}}\right)$ determination in plants and foods. The analyte was quantified by the spectrophotometric molybdenum blue method. Linear response was observed between 2.0 and $30 \mathrm{mg} \mathrm{L}^{-1} \mathrm{P}_{\mathrm{I}}$, and detection limit was estimated at $0.50 \mathrm{mg} \mathrm{L}^{-1} \mathrm{P}_{\mathrm{I}}(99.7 \%$ confidence level, $\mathrm{n}=20)$. Determination rate was estimated at $20 \mathrm{~h}^{-1}$ using in-line extraction with $20 \mathrm{mg}$ of sample. Precise timing of the flow system allowed the use of incomplete SLE for the first time prior to $\mathrm{P}_{\mathrm{I}}$ determination. The online extraction was carried out for $60 \mathrm{~s}$, leading to an extraction efficiency of $65 \pm 3 \%$ in comparison to batch quantitative extraction. The results obtained by the proposed procedure were in agreement with those obtained with batch extractions (95\% confidence level).
\end{abstract}

Keywords: flow analysis, incomplete extraction, phosphorus, sample preparation, vegetable material

\section{Introduction}

Phosphorus is an important nutrient for plants and animals because it participates in many biochemical processes. ${ }^{1,2}$ This element composes prominent biomolecules such as adenosine triphosphate (ATP), phospholipids, nucleic acids, coenzymes and inositol phosphates. Phosphorus is absorbed by living organisms mainly as orthophosphate $\left(\mathrm{H}_{2} \mathrm{PO}_{4}^{-}\right.$and $\mathrm{HPO}_{4}{ }^{2-}$ depending on $\left.\mathrm{pH}\right)$, which corresponds to non-condensed inorganic phosphorus in the water soluble fraction $\left(\mathrm{P}_{\mathrm{I}}\right)$. Regarding plant nutrition, the enzymatic conversion of organic phosphorus by phytase increases $P_{I}$ in soils. On the other hand, phosphate leaching by rain and irrigation waters decreases $\mathrm{P}_{\mathrm{I}}$ content, requiring the use of fertilizers for nutrient maintenance.

One alternative for inorganic and organic fertilizers are green manures (e.g. Crotalaria juncea), ${ }^{3}$ which basically are plants that recover soil fertility by increasing nutrient content and ion exchange capacity. Prior to a new sowing, the plants are felled, and their residues remain on the soil as nutrient supply. Therefore, determination of $\mathrm{P}_{\mathrm{I}}$ in green manures is important for agronomic studies. As $\mathrm{P}_{\mathrm{I}}$ is also readily bioaccessible for animals, its determination in

*e-mail: d.rocha@ufabc.edu.br vegetable derived foodstuffs (e.g. leguminous grains and flours) is also important for human nutritional studies.

Determination of $\mathrm{P}_{\mathrm{I}}$ in vegetable materials and solid foodstuffs requires solid-liquid extraction (SLE) of the analyte from the solid sample, which is highly susceptible to analyte losses and sample contamination. ${ }^{3,4}$ Additionally, SLE generally requires tiring and time-consuming steps such as centrifugation and filtration. The use of aqueous medium is recurrent for $\mathrm{P}_{\mathrm{I}}$ extraction, but similar efficiencies for $\mathrm{P}_{\mathrm{I}}$ removal have been reported with different extraction times and extractant composition. ${ }^{3,5,6} \mathrm{~A}$ common procedure for $\mathrm{P}_{\mathrm{I}}$ extraction from plant materials is carried out with $\mathrm{HClO}_{4}$, ${ }^{6}$ being the organic matter removed with active charcoal. $\mathrm{P}_{\mathrm{I}}$ is then determined with molybdenum blue method. One of the drawbacks is related to acidic waste generation containing perchloric acid. Alternatively, trichloroacetic acid (TCA) has been proposed for $\mathrm{P}_{\mathrm{I}}$ extraction from plant materials, but systematic errors have been reported ${ }^{7}$ due to condensed phosphorus extraction and hydrolysis caused by the hydrophobicity and the low $\mathrm{pH}$ of TCA solution, respectively.

The replacement of acids by water for $\mathrm{P}_{\mathrm{I}}$ extraction was also proposed. ${ }^{3}$ SLE was carried out for $10 \mathrm{~min}$, thus making this step cleaner and 6-fold faster than previous procedure employing acidic extraction. Afterwards, $\mathrm{P}_{\mathrm{I}}$ was 
directly determined in a monosegmented flow system with spectrophotometric detection without the clean-up step with active charcoal. In spite of that, sample preparation was not mechanized, which increases inaccuracy sources inherent to batch extractions.

Flow-based systems have been successfully employed in a versatile and robust way to minimize errors in SLE. ${ }^{8}$ These systems overcome drawbacks of batch procedures, minimizing analyte losses, sample contamination, reagent consumption, and waste generation. ${ }^{8}$ Additionally, analytical frequency and precision are enhanced in procedures employing slow reactions because detection can be carried out without reaching chemical equilibrium, also allowing the exploitation of kinetic aspects. Therefore, analysis can be performed with incomplete decomposition and extraction steps. ${ }^{9}$

In-line procedures aiming at analyte transference from solid sample to liquid phase have been scarcely exploited. ${ }^{8}$ Elemental determinations in pharmaceuticals ${ }^{10}$ and in phosphate rocks ${ }^{11}$ have been carried out after the in-line extraction using a suspension formed in a lab-made device, and carried through the analytical path. In-line filtration step and addition of suspension stabilizers were necessary. The formation of suspension has also been exploited for determination of exchangeable potassium in soils. ${ }^{12}$ In this case, the sample was transferred to an open vessel for addition of the extractant followed by the formation of the suspension. After magnetic stirring for online SLE, extracts were aspirated to a flow system for potassium determination using paper filter at the tip of the aspirating tubes.

Chambers that also entrap suspension and allow the use of smaller amounts of sample have been recently proposed for in-line SLE of nitrate from vegetables. ${ }^{13}$ A removable part of the apparatus allows sample replacement without disconnecting the whole chamber of the flow system. Additionally, magnetic stir bars were used to improve extraction. Despite appropriate for quantitative SLE extraction, incomplete processes have not been evaluated.

Simpler sample chambers have been proposed for determination of ammonium in building materials, ${ }^{14}$ and for bioavailability studies of antioxidants in foods, ${ }^{15}$ and of elements in soils ${ }^{16}$ and wastes. ${ }^{17}$ These applications showed some drawbacks such as the need for manual addition of reagents ${ }^{14}$ and collection of extracts in open vessels prior to determinations. ${ }^{15-17}$ Mechanized procedures exploiting dynamic SLE followed by in-line dilution and determination, for example, have not been exploited. In this regard, incomplete processes for SLE has also not been studied. In this work, an analytical procedure is proposed with incomplete in-line extraction of $\mathrm{P}_{\mathrm{I}}$ from vegetable materials and leguminous foods prior to direct determination with spectrophotometric molybdenum blue method.

\section{Experimental}

\section{Apparatus}

The flow manifold comprised an 8-channel peristaltic pump model IPC-8 (Ismatec, Cole Parmer, Wertheim, Germany) equipped with $1.85 \mathrm{~mm}$ i.d. Tygon ${ }^{\circledR}$ tubes (Ismatec), polyethylene tubes (0.76 mm i.d.), a pair of acrylic proportional injectors and a PEEK ${ }^{\circledR}$ 6-way confluence joint. The sample chamber was constructed with a transparent polyvinyl chloride (PVC)-based Tygon ${ }^{\circledR}$ tube (4.0 $\mathrm{cm}$ length and $4 \mathrm{~mm}$ i.d.) with glass wools in both tips to avoid the escaping of the solid material. This tube was connected to the flow system aiming at dynamic extractions.

Measurements were carried out with a modular multichannel spectrophotometer (Ocean Optics USB4000, Dunedin, FL, USA) composed by a tungsten-halogen light source, a charge-coupled device spectrometer (200-800 nm), a pair of $600 \mu \mathrm{m}$ i.d. optical fibers, and a sample holder with a $10 \mathrm{~mm}$ optical path flow cell (Hellma, Müllheim, Germany; $80 \mu \mathrm{L}$ internal volume). The software SpectraSuite ${ }^{\circledR}$ (Ocean Optics) was employed for data acquisition using an HP Intel Core i3 computer. A magnetic stirrer (Quimis, Diadema, SP, Brazil) and a centrifuge (Hettich, Kirchlengern, Germany) were also employed.

Reagents, solutions, and samples

All solutions were prepared with deionized water and analytical grade chemicals. The $\mathrm{R} 1$ reagent was a $12 \mathrm{mmol} \mathrm{L}^{-1}\left(\mathrm{NH}_{4}\right)_{6} \mathrm{Mo}_{7} \mathrm{O}_{24} \cdot 4 \mathrm{H}_{2} \mathrm{O}$ (Sigma, St. Louis, MO, USA) solution in $0.30 \mathrm{~mol} \mathrm{~L}^{-1} \mathrm{HNO}_{3}$ (Sigma). A $60 \mathrm{mmol} \mathrm{L}^{-1}$ ascorbic acid (R2, Sigma) was daily prepared by dissolving the reagent in water. Stock solution of $1000 \mathrm{mg} \mathrm{L}^{-1} \mathrm{P}_{\mathrm{I}}$ as $\mathrm{KH}_{2} \mathrm{PO}_{4}$ (Sigma) was prepared by dissolution of appropriate amounts of the salt in water. Reference solutions of $\mathrm{P}_{\mathrm{I}}$ were prepared by adequate dilution of the stock in water. Therefore, water was used as blank throughout optimization.

Soy flour and beans were purchased in a local market, and plant materials (Crotalaria juncea, coffee and fig trees) were provided by Center for Nuclear Energy in Agriculture (University of São Paulo, Brazil). These samples were cut in a knife mill (particles $<60 \mu \mathrm{m}$ ) and dried at $80^{\circ} \mathrm{C}$ until they have the same weight. Afterwards, they were kept in a desiccator. Prior to in-line extraction, no further sample treatment was carried out. 


\section{Proposed procedure}

For the extraction and determination of $\mathrm{P}_{\mathrm{I}}$, the flow manifold shown in Figures $1 \mathrm{a}$ and $1 \mathrm{~b}$ was operated. In the position showed in Figure 1a, the sample chamber (SC) containing $20 \mathrm{mg}$ of sample, and coil B1 (which defined the extractant volume) were filled with $2.5 \mathrm{~mL}$ of extractant (deionized water) at $2.5 \mathrm{~mL} \mathrm{~min}^{-1}$. The pump timer was set to $60 \mathrm{~s}$, which was the time required to fill the extraction path, and the pump was automatically turned off after that period. Afterwards, the pump was restarted after injector Inj1 was commuted in the direction represented by the white arrow in Figure 1a. In this position, water was allowed to recirculate for $60 \mathrm{~s}$ in the extraction path for $\mathrm{P}_{\mathrm{I}}$ extraction. The time was also controlled by the pump timer and the device was automatically turned off at the end of the extraction. Then, Inj1 was returned to the previous position and, after turning on the pump, water was used to transport the extract towards sample loop L1 in Inj2 by using a 50-cm coil (B2) between the injectors. By transporting the extract for $70 \mathrm{~s}$ (at $2.5 \mathrm{~mL} \mathrm{~min}^{-1}$ ), the portion of the extract zone filling the loop was proportional to the necessary dilution (2-fold when collection of the extract was performed batchwise) to avoid $\mathrm{P}_{\mathrm{I}}$ concentrations out of the linear range for $\mathrm{P}_{\mathrm{I}}$ determination. The time for this step was also controlled by the pump timer to avoid imprecise sampling. Meanwhile, reagent loops L2 and L3 were filled with R1 and R2 solutions, respectively. Pumping was restarted after injector Inj2 was commuted towards the direction showed by the white arrow in Figure 1b. The sample zone was formed by zones penetration and directed towards B3 and spectrophotometric detection at $730 \mathrm{~nm}$ using water as carrier. Sample replacement was carried out by removing the sample chamber from the system, discarding the suspension, and washing the tube with $1 \% \mathrm{HNO}_{3}$ and deionized water prior to the introduction (a)

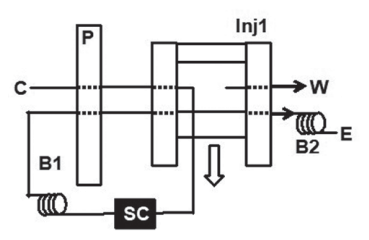

(b)

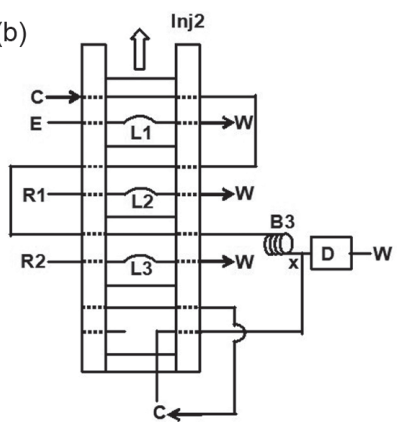

Figure 1. Flow system manifold for (a) extraction and (b) determination of soluble inorganic phosphorus. E: extract; R1: $\left(\mathrm{NH}_{4}\right)_{6} \mathrm{Mo}_{7} \mathrm{O}_{24} \cdot 4 \mathrm{H}_{2} \mathrm{O}+$ $\mathrm{HNO}_{3}$; R2: ascorbic acid; $\mathrm{C}: \mathrm{H}_{2} \mathrm{O}$; W: waste; Inj1 and Inj2: proportional injectors; L1-L3: sample and reagent loops; B1-B3: coils (90, 50, and $150 \mathrm{~cm}$, respectively); SC: sample chamber; P: peristaltic pump; D: spectrophotometric detection cell; $\mathrm{x}$ : confluence joint. The white arrows indicate the commuting direction of the injectors. of the next sample. Due to sample packing, the rising of air bubbles in the analytical path was rare. For each entrapment of sample, it was possible to register one response. Therefore, for analysis in triplicate, three different portions of the same sample had to be employed (one response for each extraction).

Extraction efficiency (EE) was evaluated by comparing $\mathrm{P}_{\mathrm{I}}$ content obtained with dynamic and batch sample preparations, considering the latter yielded quantitative extraction. Accuracy was evaluated by comparing the results obtained with the developed and batch procedures.

For $\mathrm{P}_{\mathrm{I}}$ determination, chemical and physical parameters were optimized using the flow injection system shown in Figure $1 \mathrm{~b}$ with the univariate method, aiming at maximum sensitivity and determination rate, better precision and minimum reagent consumption and waste generation. The initial concentrations and volumes were as reported before in the literature for $\mathrm{P}_{\mathrm{I}}$ determination: ${ }^{5} 25 \mu \mathrm{L}$ of $0.32 \mathrm{mmol} \mathrm{L}^{-1} \mathrm{P}\left(10 \mathrm{mg} \mathrm{L}^{-1}\right), 20 \mu \mathrm{L}$ of $7.5 \mathrm{mmol} \mathrm{L}^{-1}$ $\left(\mathrm{NH}_{4}\right)_{6} \mathrm{Mo}_{7} \mathrm{O}_{24} \cdot 4 \mathrm{H}_{2} \mathrm{O}$ in $0.15 \mathrm{~mol} \mathrm{~L}^{-1} \mathrm{HNO}_{3}$ and $40 \mu \mathrm{L}$ of $60 \mathrm{mmol} \mathrm{L}^{-1}$ ascorbic acid.

\section{Batch procedure}

For accuracy assessment, $\mathrm{P}_{\mathrm{I}}$ extraction and determination in vegetable materials and leguminous was carried out according to batch extraction procedures. ${ }^{3,5}$ In a $50-\mathrm{mL}$ polypropylene flask, $200 \mathrm{mg}$ of plant sample, and $15 \mathrm{~mL}$ of water were mixed and kept under agitation for $10 \mathrm{~min}$. Afterwards, samples were centrifuged and filtered for phase isolation. The volume was completed with water up to $20 \mathrm{~mL}$ prior to the spectrophotometric determination of $\mathrm{P}_{\mathrm{I}}$ using molybdenum blue method. For soy flour and beans, $3.0 \mathrm{~g}$ of sample was transferred to a $50-\mathrm{mL}$ polypropylene flask and suspended with $30 \mathrm{~mL}$ of deionized water. After $1 \mathrm{~h}$ of orbital agitation, the suspension was centrifuged, filtered, and the extract volume was made up to $50 \mathrm{~mL}$. The determinations were carried out batchwise using the same reaction conditions as the monosegmented flow procedure, ${ }^{3}$ by mixing the extract, a $2.5 \mathrm{mmol} \mathrm{L}^{-1}$ heptamolybdate in $0.25 \mathrm{~mol} \mathrm{~L}^{-1} \mathrm{H}_{2} \mathrm{SO}_{4}$ solution and $0.15 \mathrm{~mol} \mathrm{~L}^{-1}$ ascorbic acid solution (1.0 mL of each). The mixture rested for $10 \mathrm{~min}$, and the volume was rounded up to $5.0 \mathrm{~mL}$ with water. Spectrophotometric responses were obtained at $730 \mathrm{~nm}$.

\section{Results and Discussion}

The reaction stoichiometry of molybdenum blue (MB) is not fixed because different molybdate species are formed depending on chemical conditions, especially $\mathrm{pH}{ }^{18}$ Reaction kinetics is also easily altered, depending on the 
reducing reagent, as well as the number of generated MB species. Nevertheless, a simplified and general reaction can be represented as in equations 1 and $2^{18}$ with ascorbic acid as reducing agent.

$\mathrm{PO}_{4}{ }^{3-}+12 \mathrm{MoO}_{4}{ }^{2-}+27 \mathrm{H}^{+} \rightarrow \mathrm{H}_{3} \mathrm{PO}_{4}\left(\mathrm{MoO}_{3}\right)_{12}+$ $12 \mathrm{H}_{2} \mathrm{O}$

$\mathrm{H}_{3} \mathrm{PMo}(\mathrm{VI})_{12} \mathrm{O}_{40}+2 \mathrm{C}_{6} \mathrm{H}_{8} \mathrm{O}_{6} \rightarrow\left[\mathrm{H}_{4} \mathrm{PMo}(\mathrm{VI})_{8} \mathrm{Mo}(\mathrm{V})_{4} \mathrm{O}_{40}\right]$ $+2 \mathrm{C}_{6} \mathrm{H}_{6} \mathrm{O}_{6}+3 \mathrm{H}^{+}$

Maximum absorption and absorptivity change with the composition of reagents because of different reaction products, such as the ones containing $\mathrm{Sb} .{ }^{19} \mathrm{In}$ this work, $\mathrm{Sb}$ was neglected, as $\mathrm{P}_{\mathrm{I}}$ concentration in plant extracts does not require high sensitivity, also yielding a greener approach.

In order to yield $\mathrm{pH} 0-1^{18}$ for $\mathrm{MB}$ formation, sulfuric acid is widely employed despite the evidences that blank signals are higher in the presence of sulfate ions due to formation of species that absorb at $750-770 \mathrm{~nm}$ in the absence of phosphorus. ${ }^{18}$ Therefore, analytical signals were obtained in sulfuric and nitric acids media at the same $\mathrm{pH}$. The difference between responses was $<2 \%$, indicating that both acids can be employed. A slight increase of the blank was observed with sulfuric acid solutions, but a paired $t$-test showed that they did not differ significantly from blank signals obtained with nitric acid. Reagent R1 was then prepared with $0.15 \mathrm{~mol} \mathrm{~L}^{-1} \mathrm{HNO}_{3}$. Schlieren effect due to acidity of the sample zone was minimized with an intermittent flow of water, which also improved determination rate.

Flow-based determination of $\mathrm{P}_{\mathrm{I}}$ using zone penetration approach was exploited for the first time. As the volumes of solutions were defined by sampling loops, continuous reagent pumping was avoided, minimizing waste generation and reagents consumption. Merging zones approach was also considered, but the response decreased $42 \%$ due to the sample and reagent dilution at the confluence joint. In this condition, the order of the injected solutions did not alter the response significantly.

\section{System optimization for $P_{1}$ determination}

The first optimized parameter was sample volume, which was varied from 25 to $300 \mu \mathrm{L}$ (5.0-60 cm sample loop). The signals increased with sample volume until reaching a plateau, as expected. In spite of minimizing dispersion, the increase of the sample volume hinders the overlap of the zones, causing minimal signal variations above $200 \mu \mathrm{L}$ due to poorer mixing. Thus, this volume was selected for further studies. Maximum blank absorbance was $0.010 \pm 0.001$.
Volumes of reagents R1 and R2 were varied from 15 to $125 \mu \mathrm{L}$. Lower volumes were not studied because the injector geometry did not allow the use of loops smaller than $3.0 \mathrm{~cm}$. For R1, higher sensitivity was observed with $25 \mu \mathrm{L}$. Lower responses were observed for volumes higher than $50 \mu \mathrm{L}$ because a longer $\mathrm{R} 1$ zone increased the distance between sample and $\mathrm{R} 2$. The minimum possible volume of R2 was chosen because higher volumes did not affect the analytical signal, as R2 is at the front of the zones, and in great excess. Thus, 25 and $15 \mu \mathrm{L}$ of $\mathrm{R} 1$ and $\mathrm{R} 2$ solutions were respectively chosen.

Residence time was evaluated with the variation of reaction coil $B_{3}$ from 250 to $1000 \mu \mathrm{L}(50-200 \mathrm{~cm})$. Significant increase of the analytical signal with $\mathrm{B}_{3}$ was observed up to $750 \mu \mathrm{L}(150 \mathrm{~cm})$ because from this point reaction development did not compensate signal loss due to dispersion. Still regarding residence time, flow rate was

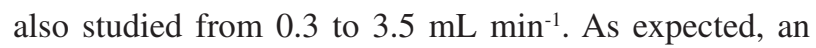
increase of the analytical signal was observed for lower flow rates. By employing 1.0 and $2.0 \mathrm{~mL} \mathrm{~min}^{-1}$, the response decreased ca. $11 \%$ with the latter, but determination rate increased 2-fold. Therefore, for $\mathrm{P}_{\mathrm{I}}$ determination, a $750 \mu \mathrm{L}$ reaction coil, and $2.0 \mathrm{~mL} \mathrm{~min}^{-1}$ flow rate were chosen for further experiments.

Intermittent flow was also exploited aiming at decreasing the cleaning time. By inserting water into the analytical path after maximum signal was obtained, the determination rate was increased in twofold due to the higher flow rate after confluence joint x. A $0.10 \mathrm{~mol} \mathrm{~L}^{-1}$ $\mathrm{NaOH}$ solution was also evaluated for cleaning, but determination rate was not significantly affected.

Phosphomolybdic acid formation and reducing reactions strongly depend on acidity and molybdate concentration, making important the optimization of reagents conditions. Nitric acid, ammonium heptamolybdate, and ascorbic acid concentrations were evaluated from 100 to $700,8.0$ to 20 and 40 to $100 \mathrm{mmol} \mathrm{L}^{-1}$, respectively. Similar response trends were observed in these studies. Analytical signal increased up to a certain concentration, and reached a plateau for higher values. The selected parameters were $300 \mathrm{mmol} \mathrm{L}^{-1} \mathrm{HNO}_{3}, 12 \mathrm{mmol} \mathrm{L} \mathrm{L}^{-1}$ ammonium heptamolybdate, and $60 \mathrm{mmol} \mathrm{L}^{-1}$ ascorbic acid. Due to the undefined reaction stoichiometry, it is not a simple task to predict which species of MB were formed. Considering the chemical conditions of the sample zone, the precursor of MB was octamolybdate..$^{18,20}$

\section{Analytical features}

After optimization, the procedure was evaluated for $P_{I}$ determination in plants, soy flour, and beans. A summary 
of the chosen parameters and the studied ranges is shown in Table 1. Linear response was observed between 2.0 and $30 \mathrm{mg} \mathrm{L}^{-1} \mathrm{P}_{\mathrm{I}}\left(64-960 \mu \mathrm{mol} \mathrm{L} \mathrm{L}^{-1}\right)$, described by equation $A=0.049 C_{P}+0.067, r=0.9998$, where $A$ is absorbance and $\mathrm{C}_{\mathrm{P}}$ is $\mathrm{P}_{\mathrm{I}}$ concentration in $\mathrm{mg} \mathrm{L}^{-1}$. Coefficient of variation $(n=20)$, detection limit $(n=20,99.7 \%$ confidence level $)$, and determination rate were estimated at $1.2 \%, 0.50 \mathrm{mg} \mathrm{L}^{-1}$ and $40 \mathrm{~h}^{-1}$, respectively. $3.0 \mathrm{~mL}$ of waste was generated per determination, consuming $55 \mu \mathrm{g}$ of $\left(\mathrm{NH}_{4}\right)_{6} \mathrm{Mo}_{7} \mathrm{O}_{24} \cdot 4 \mathrm{H}_{2} \mathrm{O}$, and $120 \mu \mathrm{g}$ of ascorbic acid.

Table 1. Optimized parameters of the flow system (Figure 1b) for determination of soluble inorganic phosphorus

\begin{tabular}{lcc}
\hline Parameter & Interval & Selected value \\
\hline Sample volume / $\mu \mathrm{L}$ & $25-300$ & 200 \\
$\mathrm{R} 1$ volume / $\mu \mathrm{L}$ & $15-125$ & 25 \\
$\mathrm{R} 2$ volume / $\mu \mathrm{L}$ & $15-125$ & 15 \\
Reaction coil length / $\mu \mathrm{L}$ & $250-1000$ & 750 \\
Flow rate / $\left(\mathrm{mL} \mathrm{min}^{-1}\right)$ & $0.3-3.5$ & 2.0 \\
$\mathrm{HNO}_{3} /\left(\mathrm{mmol} \mathrm{L}^{-1}\right)$ & $100-700$ & 300 \\
$\left(\mathrm{NH}_{4}\right)_{6} \mathrm{Mo}_{7} \mathrm{O}_{24} /\left(\mathrm{mmol} \mathrm{L}^{-1}\right)$ & $8.0-20$ & 12 \\
${\text { Ascorbic acid / }\left(\mathrm{mmol} \mathrm{L}^{-1}\right)}$ & $40-100$ & 60 \\
\hline
\end{tabular}

\section{Extraction efficiency evaluation}

For dynamic SLE of $\mathrm{P}_{\mathrm{I}}$ from vegetable materials, Crotalaria juncea was employed as a model, and water was used as extractant as previously recommended. ${ }^{3}$ Reference $\mathrm{P}_{\mathrm{I}}$ content was obtained by a batch extraction, ${ }^{3}$ and it was estimated at $1.66 \mathrm{mg} \mathrm{g}^{-1}$. This value was considered as quantitative extraction of $P_{I}$ and was used for evaluating extraction efficiency (EE). Initially, injectors Inj1 and Inj2 in Figure 1 were not connected. After flow-based extraction with $2.3 \mathrm{~mL}$ of water, the extracts were collected in $15-\mathrm{mL}$ graduated polyethylene flasks, and diluted 2-fold prior to $\mathrm{P}_{\mathrm{I}}$ determination with the manifold depicted in Figure 1b. The initial conditions for optimization were $40 \mathrm{mg}$ of sample in an 8.0-cm Tygon ${ }^{\circledR}$ tube $(4.0 \mathrm{~mm}$ i.d.), extractant flow rate and volume at $2.5 \mathrm{~mL} \mathrm{~min}^{-1}$ and $3.5 \mathrm{~mL}$, respectively. The recirculation time for extraction was initially carried out for $60 \mathrm{~s}$, which was counted from the moment that injector Inj1 was commuted in the direction of the white arrow in Figure 1a until it was returned to the initial position.

The flow rate of water during recirculation for extraction was evaluated (Figure 2a). Flow rates at 1.5 and $2.5 \mathrm{~mL} \mathrm{~min}^{-1}$ led to a difference of $\mathrm{EE}<2.0 \%$. On the other hand, higher flow rates decreased EE because the time of contact between sample and extractant was increased as the extraction is carried out in a loop. This led to a pronounced water absorption by the solid, retaining part of the extract. This means that the water containing previously extracted analyte was absorbed by the solid, hindering EE. By performing three consecutive extractions with water for $60 \mathrm{~s}$ each, and collecting the extract in a vial prior to $\mathrm{P}_{\mathrm{I}}$ determination, an EE of ca. $97 \%$ was achieved. Washing steps and sequential extractions of the same sample would be difficult to implement in the proposed flow system due to the need for entrapping several aliquots of extracts sequentially because of the volumes of coil B2 and sample loop L1 (Figure 1). As flow injection systems show highly reproducible timing, a fixed EE was achieved using flow rate at $2.5 \mathrm{~mL} \mathrm{~min}^{-1}$ with high reproducibility and determination rate.

Sample mass was evaluated by altering the volumes of sample chamber and extraction coil B1 proportionally. In this way, extractant volume remained constant during the experiments. In Figure 2b, EE was inversely proportional to sample mass, as expected. With fixed extractant volume and extraction time, higher amounts of sample decreased the contact time of the extractant with the solid. By using $40 \mathrm{mg}$, in one second, ca. $0.96 \mu \mathrm{L}$ of water was in contact with $1 \mathrm{mg}$ of sample. This volume decreases 2-fold for $80 \mathrm{mg}$, implying that poorer efficiency was due to smaller amounts of $\mathrm{P}_{\mathrm{I}}$ extracted from the sample. Additionally, extract absorption increased with the amount of solid. Therefore, sample mass was reduced to $20 \mathrm{mg}$ (in a $4.0 \mathrm{~cm}$ tube). Lower masses were not evaluated to avoid errors related to sample weighing.

Extractant volume and extraction time were evaluated from 1.8 to $2.5 \mathrm{~mL}$ (Figure 2c), and from 60 to $300 \mathrm{~s}$ (Figure 2d), respectively. The former was studied by altering the volume of extraction coil B1 (Figure 1a). For the latter, the time for recirculation was varied. In both studies, the increased contact time between sample and water (lower volumes of water and higher extraction times) led to poorer EE. This was also observed when flow rate was evaluated, as previously discussed. Water absorption by the sample was noted because of the slight decrease of extract volume $(<100 \mu \mathrm{L})$ after collection in the vials. Therefore, $2.5 \mathrm{~mL}$ of extractant and $60 \mathrm{~s}$ recirculation time were selected. Shorter extraction times were not evaluated due to the time needed for a complete turn of the extract in the extraction path.

After optimization, EE of Crotalaria juncea was estimated at $65 \pm 3 \%(\mathrm{n}=5)$. Aiming at analytical application to other plant materials, the comparison between batch and dynamic extractions were carried out for leaves and stem of coffee and fig trees $(n=5)$, leading to extraction efficiencies of $65 \pm 3$ and $63 \pm 4 \%$, respectively. 

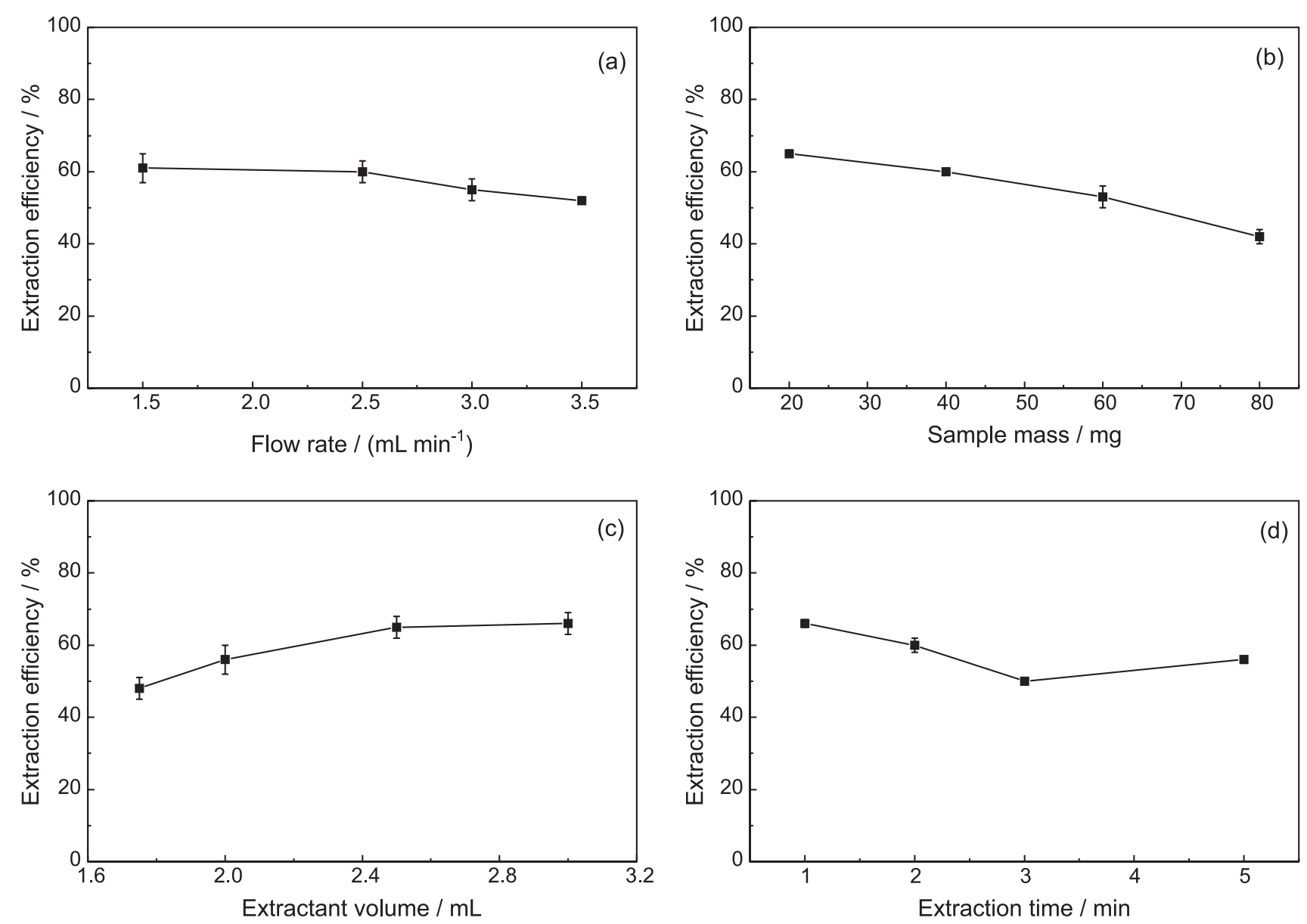

Figure 2. Variation of online extraction efficiency with (a) extractant flow rate; (b) sample mass; (c) extractant volume; and (d) recirculation time.

These samples originated from Coffea sp. and Ficus carica. For soy flour and beans, EE reached $69 \pm 4 \%$. This value was not statistically different from EE of plants $(95 \%$ confidence level). In-line extraction led to coefficients of variation $<5.0 \%$, which is lower than the observed for batch extractions $(<15 \%)$, demonstrating better reproducibility of the proposed procedure.

The direct transportation of the extract from Inj1 (Figure 1a) towards sample loop L1 of Inj2 (Figure 1b) was evaluated to avoid the collection of the extract in vessels prior to determination of $\mathrm{P}_{\mathrm{I}}$. As a twofold dilution was required for analysis, the concentration gradient of the extract was exploited to yield this condition for $\mathrm{P}_{\mathrm{I}}$ determination. Therefore, a 50 -cm tube $(0.76 \mathrm{~mm}$ i.d. $)$ was employed to connect the extract outlet of Inj1 to sample loop inlet of Inj2. The time was controlled by using the peristaltic pump timer. Signals obtained for a sample of Crotalaria juncea after in-line extraction followed by 2 -fold dilution in vials, and direct determination after $70 \mathrm{~s}$ transportation were $0.325 \pm 0.005$ and $0.337 \pm 0.006$, respectively. The signals did not show significant difference at 95\% confidence level $(n=3)$, indicating that a twofold dilution was achieved with both conditions. Depending on the required dilution, the time for transportation can be varied with coil length, and flow rate. Considering the time for in-line extraction and determination of $\mathrm{P}_{\mathrm{I}}$, sample throughput was estimated at $20 \mathrm{~h}^{-1}$. As the sample chamber is cheap and easily constructed (comprising a simple polymeric tube), several samples can be prepared, and the dynamic extractions can be carried out sequentially by changing the sample. After extraction, the sample chambers can be disposed or reused after washing with diluted nitric acid, and water.

\section{Application and critical evaluation}

Results of the analysis of plant and food extracts by the proposed procedure were compared with those obtained by batch procedures ${ }^{3,5}$ described in "Batch procedure" sub-section. Table 2 shows the comparison of results for samples analyzed with the manifold in Figure $1 \mathrm{~b}$ using batch (Crotalaria 3, soy flours, and beans) and dynamic (Crotalaria 1-3, coffee and fig trees, and soy flours) extractions. In this way, the accuracy of $\mathrm{P}_{\mathrm{I}}$ determination 
was assessed after batch and in-line extractions. The results agreed with the attained by the batch procedures $(95 \%$ confidence level), considering the EE of $65 \%$.

The proposed procedure is faster and cleaner than other strategies for extraction and determination of $\mathrm{P}_{\mathrm{I}}$. In comparison to a reported procedure, ${ }^{3}$ this work showed 10-fold higher detection limit due to the shorter residence time. This feature is not critical for $\mathrm{P}_{\mathrm{I}}$ determination in vegetable materials. On the other hand, the consumption of molybdate and ascorbic acid were 15 and 40-fold lower, respectively. Extraction time was reduced 10-fold using significative lower amounts of sample and extractant. Reagent consumption was also decreased compared to a proposed procedure for determination of $\mathrm{P}$ species in foodstuffs using multicommutation. ${ }^{5}$ In spite of the advantages of solenoid micro pumps for solution handling and automation, reagent consumption was 7 -fold higher than the proposed procedure with similar detection limit $\left(0.5 \mathrm{mg} \mathrm{L}^{-1} \mathrm{P}_{\mathrm{I}}\right)$. In comparison to a reference procedure for $\mathrm{P}_{\mathrm{I}}$ extraction in plant materials, ${ }^{6}$ this work did not employ neither mineral acids for extraction nor active charcoal for clean-up steps. In all previous works, phosphorus extractions were carried out batchwise, affecting analytical frequency and reproducibility.

Table 2. Main values and uncertainties for soluble inorganic phosphorus determination in plant materials, soy flours, and beans by the proposed and batch procedures

\begin{tabular}{lcc}
\hline \multirow{2}{*}{ Sample } & \multicolumn{2}{c}{ Soluble inorganic phosphorus / $\left(\mathrm{mg} \mathrm{g}^{-1}\right)$} \\
\cline { 2 - 3 } & Proposed procedure & Batch procedure ${ }^{3,5}$ \\
\hline${\text { Crotalaria } 1^{\mathrm{a}}}_{\text {Crotalaria }^{\mathrm{a}}{ }^{\mathrm{a}}}$ & $1.75 \pm 0.01^{\mathrm{b}}$ & $1.73 \pm 0.03$ \\
${\text { Crotalaria } 3^{\mathrm{a}}}$ & $1.49 \pm 0.01^{\mathrm{b}}$ & $1.59 \pm 0.02$ \\
Coffee $^{\mathrm{a}}$ & $1.80 \pm 0.01^{\mathrm{b}}$ & $1.79 \pm 0.01$ \\
Fig $^{\mathrm{a}}$ & $1.74 \pm 0.01^{\mathrm{c}}$ & $1.79 \pm 0.01$ \\
Soy flour 1 & $0.260 \pm 0.01^{\mathrm{b}}$ & $0.270 \pm 0.01$ \\
Soy flour 2 $^{\mathrm{b}}$ & $1.11 \pm 0.03^{\mathrm{b}}$ & $1.14 \pm 0.02$ \\
& $1.18 \pm 0.01^{\mathrm{c}}$ & $1.17 \pm 0.02$ \\
Beans 1 & $1.13 \pm 0.02^{\mathrm{b}}$ & $1.17 \pm 0.02$ \\
Beans 2 & $1.47 \pm 0.01^{\mathrm{c}}$ & $1.19 \pm 0.02$ \\
\hline
\end{tabular}

aLeaves and stem; bdynamic extraction; cbatch extraction.

Recent works ${ }^{10,11,13}$ have proposed SLE in flowbased systems with elaborated chambers that might perform agitation and filtering. In this work, stirring and washing steps were not necessary during the dynamic process because incomplete extractions were exploited reproducibly. Additionally, slurries were not formed in the extraction path because the solid was trapped by glass wools at both tips of the chamber. Online SLE approaches have also been proposed using simple units for extraction aiming at bioavailability studies, ${ }^{15,17}$ but direct determination after dynamic extractions have not been exploited.

The comparison of some important features of proposed procedures is presented in Table 3. In this work, sample mass was similar to or smaller than other procedures with dynamic SLE (from 0.010 to $2.0 \mathrm{~g}$ ). As determination of $\mathrm{P}_{\mathrm{I}}$ is carried out after incomplete extraction, a shorter time for extracting the analyte $(60 \mathrm{~s})$ was achieved compared to most procedures. This comparison should not be extended to dynamic extractions for bioavailability studies because they require longer periods due to multiple extractions. Another feature is that washing step of the sample is not required as normally is necessary in quantitative processes. ${ }^{13}$

Direct analyte determination after extraction is also an inherent feature of the proposed procedure. Most strategies using dynamic SLE require sample collection in vials, ${ }^{15,16}$ and separation units ${ }^{10-12}$ (e.g. filtration) prior to determinations. Additionally, the whole system is mechanized, avoiding manual solution handling as previously proposed. ${ }^{1}$

\section{Conclusions}

A flow-based procedure with in-line SLE for $\mathrm{P}_{\mathrm{I}}$ was developed and successfully applied to the accurate analysis of vegetable materials and solid foodstuffs. Reagent consumption was low, especially due to the zone penetration approach for $\mathrm{P}_{\mathrm{I}}$ determination, and the employment of water as extractant. The analytical features demonstrated the potential of the system for $\mathrm{P}_{\mathrm{I}}$ determination. In addition, sample and extractant consumptions, extraction time, and waste generation were minimized in comparison to other proposed procedures.

Incomplete extraction was applied for analytical ends due to the reproducible timing of the flow system, allowing faster determination of $\mathrm{P}_{\mathrm{I}}$. A simple chamber for sample entrapment was used, encompassing a polymeric tube with two small pieces of glass wool. In this way, the procedure does not require neither expensive nor laborious devices for extraction.

The procedure is then a reliable alternative for phosphorus determination, bringing advantages of incomplete in-line sample preparation. Agronomic studies can be benefited by in-line SLE, as well as laboratories for routine analysis of solid foodstuffs. 
Table 3. Analytical features of some procedures with in-line and online solid-liquid extraction

\begin{tabular}{|c|c|c|c|c|c|c|}
\hline Procedure & Extraction strategy & $\begin{array}{l}\text { Sample } \\
\text { mass / mg }\end{array}$ & $\begin{array}{c}\text { Extractant } \\
\text { volume / } \mu \mathrm{L}\end{array}$ & $\mathrm{RSD} / \%$ & $\begin{array}{c}\text { Extraction } \\
\text { time / s }\end{array}$ & Reference \\
\hline $\begin{array}{l}\text { Phosphorus in plants } \\
\text { and foods }\end{array}$ & entrapped sample in a Tygon ${ }^{\circledR}$ tube & 20 & 2500 & $<3.0$ & 60 & this work \\
\hline Nitrate in vegetables & $\begin{array}{l}\text { entrapped sample in a lab-made chamber } \\
\text { constructed with Perspex and paper filter }\end{array}$ & 10 & 500 & 4.0 & 120 & 13 \\
\hline $\begin{array}{l}\text { Exchangeable } \\
\text { potassium in soils }\end{array}$ & $\begin{array}{l}\text { suspension formation in an open vessel for } \\
\text { magnetic stirring; extract aspiration with a tube } \\
\text { containing a filter device }\end{array}$ & 1800 & 9000 & $<5.4$ & 360 & 12 \\
\hline $\begin{array}{l}\text { Ammonium in } \\
\text { building materials }\end{array}$ & $\begin{array}{l}\text { sample in a capped glass vial in an ultrasonic } \\
\text { bath; manual reagent addition and analyte } \\
\text { transport with inert gas flow }\end{array}$ & 200 & 3000 & $<6.0$ & 300 & 14 \\
\hline $\begin{array}{l}\text { Antioxidants in } \\
\text { cereals }\end{array}$ & $\begin{array}{l}\text { sample entrapment between two connected } \\
\text { syringe filters with cellulose membrane; extract } \\
\text { collection in vials }\end{array}$ & 40 & 5000 & $<2.0$ & 900 & 15 \\
\hline $\begin{array}{l}\mathrm{Fe}, \mathrm{Cu} \text { and } \mathrm{Zn} \text { in } \\
\text { tablets }\end{array}$ & $\begin{array}{l}\text { sample insertion in a lab-made chamber and } \\
\text { suspension formation for extraction prior to } \\
\text { analyte retention onto a cationic resin surface }\end{array}$ & 300 & 7000 & 2.0 & 210 & 10 \\
\hline $\begin{array}{l}\text { Fluoride in phosphate } \\
\text { rocks }\end{array}$ & $\begin{array}{l}\text { sample insertion in a lab-made chamber, } \\
\text { extraction based on suspension formation and } \\
\text { filtration }\end{array}$ & 50 & 6000 & $<4.0$ & 300 & 11 \\
\hline $\begin{array}{l}\text { Trace elements in } \\
\text { soil }\end{array}$ & $\begin{array}{l}\text { sample in a polysulfone column with PTFE } \\
\text { membranes at the far ends }\end{array}$ & $1000-2000$ & 10000 & $4-18$ & 120 & 17 \\
\hline $\begin{array}{l}\text { Metal ions } \\
\text { fractionation in soil }\end{array}$ & $\begin{array}{l}\text { entrapment in a lab-made PEEK chamber with } \\
\text { caps and filters at both ends }\end{array}$ & 25 & 50000 & 5.0 & 1500 & 16 \\
\hline
\end{tabular}

RSD: relative standard deviation; PTFE: polytetrafluoroethylene.

\section{Acknowledgments}

The authors acknowledge the fellowships and financial support from Brazilian agencies Coordination for the Improvement of Higher Education Personnel (CAPES) and São Paulo Research Foundation (FAPESP), process No. 2015/12172-6.

\section{References}

1. Schachtman, D.; Reid, R.; Ayling, S. M.; Plant Physiol. 1998, 116, 447.

2. Reddy, N. R. In Food Phytates, $1^{\text {st }}$ ed.; Reddy, N. R.; Sathe, S. K., eds.; Taylor \& Francis Group: Boca Raton, USA, 2001, p. 25 .

3. Maruchi, A. K.; Rocha, F. R. P.; Microchem. J. 2006, 82, 207.

4. Rocha, D. L.; Batista, A. D.; Rocha, F. R. P.; Donati, G. L.; Nóbrega, J. A.; TrAC, Trends Anal. Chem. 2013, 45, 79.

5. Rocha, D. L.; Rocha, F. R. P.; Microchem. J. 2013, 109, 139.

6. Hogue, E.; Wilcox, G. E.; Cantliffe, D. J.; J. Am. Soc. Hortic. Sci. 1970, 95, 174.

7. Noack, S. R.; Smernik, R. J.; McBeath, T. M.; Armstrong, R. D.; McLaughlin, M. J.; Talanta 2014, 126, 122.
8. Trojanowicz, M.; Kołacińska, K.; Analyst 2016, 141, 2085.

9. Rocha, D. L.; Kamogawa, M. Y.; Rocha, F. R. P.; Anal. Chim. Acta 2015, 896, 11.

10. Sweileh, J. A.; Microchem. J. 2000, 65, 87.

11. Sweileh, J. A.; Anal. Chim. Acta 2007, 581, 168.

12. Almeida, M. I. G. S.; Segundo, M. A.; Lima, J. L. F. C.; Rangel, A. O. S. S.; Microchem. J. 2006, 83, 75.

13. Galvis-Sánchez, A. C.; Santos, J. R.; Rangel, A. O. S. S.; Anal. Bioanal. Chem. 2016, 408, 7651.

14. Timofeeva, I. I.; Bulatov, A. V.; Moskvin, A. L.; Kolev, S. D.; Talanta 2015, 142, 140.

15. Maia, M. A.; Soares, T. R. P.; Mota, A. I. P.; Rosende, M.; Magalhães, L. M.; Miró, M.; Segundo, M. A.; Talanta 2017, 166, 162.

16. Chomchoei, R.; Miró, M.; Hansen, E. H.; Shiowatana, J.; Anal. Chim. Acta 2005, 536, 183.

17. Rosende, M.; Miró, M.; Cerdà, V.; Anal. Chim. Acta 2010, 658, 41.

18. Nagul, E. A.; McKelvie, I. D.; Worsfold, P.; Kolev, S. D.; Anal. Chim. Acta 2015, 890, 60.

19. Murphy, J.; Riley, J. P.; Anal. Chim. Acta 1962, $27,31$.

20. Cruywagen, J. J.; Draaijer, A. G.; Heyns, J. B. B.; Rohwer, E. A.; Inorg. Chim. Acta 2002, 331, 322. 